\title{
Educação, Trabalho e Formação Humana no Ensino Médio Integrado: uma análise dos planos pedagógicos dos cursos do IFPB/campus Guarabira e campus Sousa
}

\author{
Education, Work and Human Formation in Integrated High School: an \\ analysis of the courses pedagogical plans of the IFPB/campus Guarabira \\ and campus Sousa
}

Recebido: 19/06/2021 | Revisado: 05/08/2021 | Aceito: $26 / 10 / 2021$ |

Publicado: $1702 / 2021$

Claudia Maria Bezerra da Silva ORCID: https://orcid.org/0000-0003-19587772

Universidade Federal de Pernambuco E-mail: claudiambezerra@yahoo.com.br

Como citar:

SILVA, C. M. B.; Educação, Trabalho e Formação Humana no Ensino Médio Integrado: uma análise dos planos pedagógicos dos cursos do IFPB/campus Guarabira e campus Sousa. Revista Brasileira da Educação Profissional e Tecnológica, [S.I.], v. 1, n. 20, p. e10527, fev. 2021. ISSN 2447-1801. Disponível em: $<$ http://www2.ifrn.edu.br/ojs/index.php/RBE PT $>$.

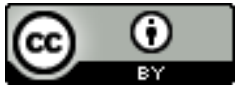

This work is licensed under a Creative Commons Attribution 4.0 Unported License.

\begin{abstract}
Resumo
Este artigo apresenta uma pesquisa que tem como finalidade refletir sobre os aspectos pertinentes à relação que se estabelece entre a educação e o trabalho em busca da formação humana integral do aluno do Ensino Médio Integrado. Para os procedimentos de pesquisa foi realizada revisão da literatura e análise de documentos. $O$ tratamento dos dados se deu por meio da análise de conteúdo. Buscouse nos Planos Pedagógicos dos Cursos do Ensino Médio Integrado do Instituto Federal de Educação, Ciência e Tecnologia da Paraíba/Campus Guarabira e Campus Sousa como as relações entre educação, trabalho e formação humana estão colocadas. Constata-se nos documentos evidências da intencionalidade formativa fundamentada na politecnia e na escola unitária que tem como perspectiva a formação humana em sua totalidade.
\end{abstract}

Palavras-Chave: Educação; Trabalho; Formação Humana; Ensino Médio Integrado.

\begin{abstract}
This article presents a research that aims to reflect on the aspects pertinent to the relationship established between education and work in search of the integral human education of the integrated high school student. For the research procedures, a literature review and document analysis were performed. The treatment of the data took place through the content analysis. In the Pedagogical Plans of the courses of integrated high school of the Instituto Federal de Educação, Ciência e Tecnologia/ Campus Guarabira and Campus Sousa it was looked for how the relations between education, work and human formation are approached. There is evidence in the documents of formative intentionality based on polytechnic and the unitary school, that has the perspective of integral human education.
\end{abstract}

Keywords: Education; Work; Human Formation; Integrated High School. 


\section{INTRODUÇÃO}

A construção de uma educação que tem o trabalho como constituinte do ser social se baseia no princípio democrático de igualdade que vai além da mera formação de mão de obra requerida pelo mercado. Decorre da valorização do acesso aos conhecimentos científicos e tecnológicos que servem de fundamento à produção, significando que não se trata de treinar eficientemente os alunos em uma técnica, mas de promover uma formação integral que tem como perspectiva a emancipação humana.

Caminhando nessa direção, o Ensino Médio Integrado (EMI) representa uma estratégia fundamentada na luta pela superação do dualismo estrutural da sociedade e da educação brasileira, que tem como marco regulatório o Decreto no 5.154/2004. Constituindo a união do ensino médio e da formação profissional, o EMI tem o entendimento de que a política assistencialista ou de ajustamento às demandas do mercado de trabalho tendem a ser ultrapassados. É uma busca pelo "[...] direito a uma formação completa para a leitura do mundo e para a atuação como cidadão pertencente a um país" (CIAVATTA, 2005, p. 3) e que encontra na educação politécnica e na escola unitária as bases para ser desenvolvida (RAMOS, 2017).

Integrar o trabalho e a educação na formação humana vai ao encontro da perspectiva da educação politécnica de Marx e Engels, que fundamentam a necessidade de apropriação dos conhecimentos científicos e tecnológicos. A educação politécnica complementada com o ideário da escola unitária de Gramsci busca romper com a dicotomia entre educação básica e técnica, resgatando o princípio da formação humana em sua totalidade. Sob essas bases, a formação profissional adquire um significado do trabalho como necessário para a constituição do homem como sujeito histórico-social que cria e modifica a própria existência, capaz de produzir saberes e agir social e politicamente.

Diante do exposto, este artigo apresenta uma pesquisa que tem como objetivo refletir sobre os aspectos pertinentes à relação que se estabelece entre a educação e o trabalho em busca da formação humana integral do aluno do EMI. Para tanto, realizamos a revisão da literatura alicerçando a discussão em Ciavatta (2005), Marx e Engels (2011), Gramsci (2001), entre outros. Também fizemos análise documental dos Planos Pedagógicos dos Cursos (PPC's) do Instituto Federal de Educação, Ciência e Tecnologia da Paraíba (IFPB)/Campus Guarabira e Campus Sousa, para identificar como as relações entre educação, trabalho e formação humana estão colocadas e os aspectos da integração do ensino médio à formação profissional.

Para melhor localizar o leitor, o texto apresenta uma discussão sobre a formação humana integral do aluno do EMI, tendo o trabalho como elemento constitutivo. Em seguida, o espaço está destinado à apresentação do percurso metodológico da pesquisa e, por fim, à análise dos PPC's e as considerações finais. 


\section{AS CONTRIBUIÇÕES DE MARX, ENGELS E GRAMSCI PARA A RELAÇÃO ENTRE EDUCAÇÃO E TRABALHO}

A partir de Marx e Engels, é possível refletir sobre a educação como possibilidade para a formação do homem plenamente desenvolvido em suas potencialidades e não subjugado ao domínio do capital. Esse pensamento representa um marco que influenciou a formulação de outras abordagens baseadas no princípio democrático da igualdade, dentre os quais sobressai Gramsci. Assim, Marx e Engels e Gramsci trazem contribuições para a construção da classe trabalhadora de modo a pensar em uma formação do sujeito preparado para as variáveis da atividade produtiva. Isso significa:

[...] substituir o indivíduo parcial, mero fragmento humano que repete sempre uma operação parcial, pelo indivíduo integralmente desenvolvido para 0 qual as diferentes funções sociais não passariam de formas diferentes e sucessivas de sua atividade. (MARX; ENGELS, 2011, p. 98).

É uma perspectiva oposta ao operário preso à realização de atividades detalhadas, mantido como reserva às necessidades capitalistas, pelo trabalhador que pudesse atuar diante das constantes configurações da fábrica. Nesse contexto, o papel da educação é o de contribuir para acabar com a separação entre intelectuais e trabalhadores, a partir da união entre o saber e o fazer (MARX; ENGELS, 2011). Já o trabalho deve ser o elemento central na formação que aconteceria diretamente em situações reais do processo produtivo, ganhando os contornos de sua natureza humana e o seu caráter histórico (MARX; ENGELS, 2011).

O trabalho é, portanto, constituinte do ser social emergindo como categoria fundamental no processo formativo do pensamento marxista. É uma busca pela superação da sociedade capitalista por meio da unicidade entre o manual e 0 intelectual, resistindo aos males da divisão, da alienação e das condições precárias de trabalho.

Em Gramsci (2001), o trabalho também é o elemento constitutivo da formação. Mas diferindo-se de Marx e Engels que se ocuparam do tema educação apenas inserido na discussão de questões sociais mais amplas, Gramsci entrega-se a ela de forma bem mais aprofundada. Assim, traz a perspectiva da escola unitária com o papel de conciliar o trabalho como princípio educativo e a transmissão da cultura clássica e moderna, atendendo aos interesses da classe trabalhadora (GRAMSCI, 1988).

A escola unitária tem uma essência humanista que ultrapassa a dicotomia entre conhecimento teórico e prático (GRAMSCI, 2001). Desse modo, o trabalho adquire o significado de princípio educativo para desenvolver em cada indivíduo a capacidade de saber pensar e dirigir-se na vida à medida que proporciona a compreensão do processo histórico, científico e tecnológico da produção.

Dentro do contexto da educação italiana que permeia o pensamento de Gramsci, a escola unitária seria uma alternativa em substituição à profusão de 
escolas profissionais do século $X X$ nas quais o ensino técnico separava o conhecimento, desvalorizando o trabalhador. Foi uma constatação de que a escola dualista tradicional apenas perpetuava as discriminações sociais com cursos profissionais para trabalhadores, enquanto a classe mais favorecida socioeconomicamente frequentava as escolas de formação geral para o ingresso na universidade.

A superação dessa dualidade se faz necessária para substituir o modelo formativo imposto pelo capital aos operários. Significa o horizonte de uma educação para que o aluno apreenda não apenas um saber prático, mas todo o processo da produção fabril, tendo o trabalho como categoria fundamental e princípio essencial da prática educativa. Assim, as contribuições de Marx, Engels e Gramsci para a relação entre educação e trabalho se encaminham na direção de uma formação integral para que o homem consiga superar a condição de adestramento e de exploração que o capitalismo o submete.

\subsection{EDUCAÇÃO POLITÉCNICA E A FORMAÇÃO UNITÁRIA E MULTILATERAL DO HOMEM}

Pensar em uma educação emancipatória capaz de colaborar com as transformações da sociedade em suas dimensões política e econômica significa, na perspectiva aqui adotada, situá-la na concepção da politecnia. Proveniente de Marx e Engels, a educação politécnica surge a partir das relações capitalistas de produção e da proposta de superação, retirando a classe trabalhadora de sua condição de subalternidade e submissão. Para isso, seria necessário aos operários deterem saberes que ultrapassam aqueles relacionados ao manejo de máquinas, tendo como referência a formação humana em seu sentido pleno. A educação é, então, compreendida como capaz de envolver:

1) Educação intelectual.

2) Educação corporal, tal como a que se consegue com os exercícios de ginástica e militares.

3) Educação tecnológica, que recolhe os princípios gerais e de caráter científico de todo o processo de produção e, ao mesmo tempo, inicia as crianças e os adolescentes no manejo de ferramentas elementares dos diversos ramos industriais (MARX; ENGELS, 2011, p. 85).

Alicerçada nesses três eixos, Marx e Engels (2011) sinalizam uma preparação multilateral do homem, em suas capacidades físicas e mentais, que contempla: os conhecimentos científicos para assimilação do processo produtivo; o trabalho corporal para recuperação física da atividade laboral; e os conhecimentos tecnológicos para o domínio dos princípios e do manejo da produção na fábrica.

Para sua realização, a educação politécnica tem a especificidade de acontecer para e por meio do trabalho, sobressaindo a compreensão de superar a dicotomia entre teoria e prática em um movimento de planejamento e ação em torno de uma realidade concreta. Afinal, uma prática esvaziada de teoria e uma teoria 
desprovida de prática são incoerentes com o entendimento de trabalho como processo integral que envolve todas as capacidades humanas (MARX, 1996).

Nesse movimento, a educação tecnológica é particularmente importante na proposição marxiana, já que é pela sua mediação que, com maior propriedade, pode ser produzida a relação teoria e prática implicando o conhecimento das bases científicas e a aplicação dos diferentes processos produtivos. A integração entre as capacidades de pensar e de produzir como imprescindível para se instaurar uma lógica educativa voltada para os trabalhadores seria uma estratégia de enfrentamento da dualidade em que se tem uma formação voltada para o manual e, de outro lado, para o intelectual. A educação politécnica, além de respeitar as inclinações e aptidões do trabalhador, representa uma diluição das diferenças entre as classes sociais, dando espaço a uma sociedade verdadeiramente democrática.

O fundamento da educação politécnica está presente na perspectiva da escola unitária de Gramsci, de onde deverá emergir o cidadão completo e consciente de sua função e importância na sociedade. A escola unitária concebe o trabalho como princípio educativo para a apropriação e a compreensão dos conhecimentos científicos e tecnológicos, contribuindo para a formação integral e para a emancipação do homem (GRAMSCI, 2001).

Esse ideário busca a adoção de uma escola única, destinada a todos os alunos, para propiciar:

[...] uma cultura geral, humanista, formativa, que equilibre equanimemente o desenvolvimento da capacidade de trabalhar manualmente (tecnicamente, industrialmente) e o desenvolvimento das capacidades de trabalho intelectual (GRAMSCI, 1988, p. 118).

É uma escola desinteressada, caracterizada pelo empenho em promover uma educação integral e ativa, para articular a formação do sujeito e transformá-lo em especialista + político (GRAMSCl, 2001). Assim, desloca a formação específica para um momento de maior maturação da personalidade do aluno, quando teria mais autonomia para escolher a carreira profissional.

Como vimos, há uma convergência nas produções de Marx e Engels e de Gramsci em assumir o trabalho como base da formação na perspectiva da emancipação humana. Neste estudo, assumimos a concepção de EMI como caminho possível para uma educação politécnica e unitária destinada à superação da dualidade de formação entre trabalho manual e intelectual. Apenas uma educação que valoriza o trabalho nas suas dimensões técnica, científica e política pode estar comprometida com a formação plena, combatendo as privações sofridas pela divisão da sociedade em classes e pela concepção do homem como força produtiva.

\section{O ENSINO MÉDIO INTEGRADO FRENTE AO HISTÓRICO DUAL DA EDUCAÇÃO BRASILEIRA}

Os primeiros indícios do que hoje pode ser caracterizado como as origens da introdução da formação para o trabalho em instituições educacionais no Brasil 
surgem no século XIX com a criação do Colégio das Fábricas, da Escola de Belas Artes e do Instituto Comercial no Rio de Janeiro. A partir de então, a educação brasileira traz em seu histórico uma dualidade na formação oferecida que distinguia os que pensavam daqueles que apenas executavam uma função. É uma trajetória com ciclos de políticas públicas adaptados ao contexto político, econômico, cultural e social de cada período, predominando o conservadorismo das elites que reservava para si a formação literária e científica enquanto que para a classe trabalhadora prevalecia a oferta de preparo para atividades manuais.

Com isso, as políticas públicas se resumiram ao caráter economicista da educação, com uma visão que não conseguia avançar na perspectiva de uma escola unitária para todos e que superasse a divisão entre a formação para o trabalho manual e intelectual estabelecida pelo pensamento da sociedade em classes. Confirma, então, o que Azevedo (2004) aponta que nas políticas públicas, as estruturas de poder e de dominação existentes no país em cada época acabam sendo referência principal nas instituições do Estado, sobretudo, na máquina governamental.

A possibilidade da preparação para o trabalho tendo um significado mais amplo do que simplesmente para desenvolver uma função aparece na Lei de Diretrizes e Bases da Educação Nacional (LDB) no 9.394/1996 que traz no Artigo 1o que "A educação escolar deverá vincular-se ao mundo do trabalho e à prática social", tendo como finalidade apresentada no Artigo $2^{\circ}$ " $[\ldots]$ o pleno desenvolvimento da pessoa, seu preparo para o exercício da cidadania e sua qualificação para o trabalho". E ainda aponta no Artigo 35 para o ensino médio como etapa final da educação básica que proporcione "[...] a compreensão dos fundamentos científico-tecnológicos dos processos produtivos, relacionando a teoria com a prática" (BRASIL, 1996).

Esses fragmentos permitem a reflexão sobre educação e trabalho como importantes quando se pensa num espaço de construção da emancipação humana. Nesse contexto, o EMI pode ser um meio de formação que habilite o sujeito a desempenhar com competência e autonomia intelectual as suas atribuições, desenvolvendo permanentemente as aptidões para a vida produtiva e social.

O EMI tem como marco regulatório o Decreto oㅜ 5.154/2004, representando um avanço em respeito à diversidade da realidade social brasileira, na busca pela superação do dualismo estrutural da educação. É a inclusão no contexto histórico de uma formação com o horizonte da educação politécnica e da escola unitária, proporcionando a compreensão dos conhecimentos científicos e tecnológicos a todos os cidadãos, independente de classe social.

O EMI tem no Documento Base da Educação Profissional Técnica de Nível Médio Integrada ao Ensino Médio, publicado em 2007, uma referência que aborda seus princípios e fundamentos, subsidiando a implementação da política pública nas escolas. Nesse documento, as categorias sobre as quais se ergue o EMI são: formação humana integral; trabalho, ciência, tecnologia e cultura como categorias indissociáveis da formação humana; trabalho como princípio educativo; pesquisa como princípio educativo; e relação parte-totalidade na proposta curricular (BRASIL, 2007). É um ideário no qual a noção de formação humana integral remete aos conceitos de educação politécnica de Marx e Engels, e de escola unitária de Gramsci. 
Com isso, é possível compreender o EMI a partir de três dimensões distintas, porém entrecruzadas, que emergem dos princípios trazidos pelo Documento Base, que são: a superação da dualidade estrutural, a politecnia e a escola unitária. Logo, a aprendizagem dos aspectos técnicos é necessária para a inserção do estudante no mundo do trabalho. Já a formação geral é igualmente importante, pois, sem ela, o estudante não tem como compreender o todo, ficando limitado aos conteúdos específicos do curso. E é nessa articulação entre o entre o pensar e o fazer, e entre a teoria e a prática, que reside a essência do EMI.

Um processo educativo que se afasta da mera transmissão de conteúdos e de técnicas significa "[...] tornar íntegro, inteiro, o ser humano dividido pela divisão social do trabalho entre a ação de executar e a ação de pensar, dirigir ou planejar." (CIAVATTA, 2005, p. 2). Com sujeitos dotados de conhecimentos científicos e tecnológicos, podem ser capazes de agir criticamente sobre as demandas sociais e do trabalho. A escola enquanto instituição que constrói, sistematiza e socializa 0 conhecimento assume a tarefa de não se limitar ao conteúdo técnico operacional, mas contextualizar as demandas da economia e da sociedade com as práticas exercidas em seu interior.

\section{METODOLOGIA}

Este artigo teve sua construção teórica realizada por meio da revisão da literatura e da análise documental. A revisão da literatura permitiu estabelecer um diálogo reflexivo a partir das abordagens de autores como Ciavatta (2005), Marx e Engels (2011), Gramsci (2001), entre outros. E consultados documentos tendo como fontes os oficiais do Governo Federal relacionados à educação brasileira e ao EMI, como a LDB no 9.394/1996 e Decreto № 5.154/2004.

Também realizamos análise documental dos PPC's do IFPB/Campus Guarabira (IFPB, 2012a; 2013; 2012b) e Campus Sousa (IFPB, 2014a; 2014b; 2016a; 2016b), para identificar como as relações entre educação, trabalho e formação humana estão colocadas e os aspectos da integração do ensino médio à formação profissional.

Para a análise dos dados nos PPC's, foi realizada a análise de conteúdo categorial na perspectiva de Bardin (2016). Assim, partimos da pré-análise dos documentos, buscando elementos linguísticos que possuíssem o mesmo valor semântico para a construção das categorias de análise. Em seguida, realizamos a análise propriamente dita a partir das categorias analíticas criadas e, por fim, a interpretação dos resultados obtidos. Foram utilizadas como categorias analíticas relacionadas à formação no EMl: integração dos fundamentos científicos $e$ tecnológicos; e trabalho, educação e emancipação humana.

Os PPC's são instrumentos teórico-metodológicos que definem o perfil de conclusão, a metodologia, os conteúdos, as competências básicas, os saberes e os princípios norteadores dos cursos. A opção por fazer a análise desses documentos se justifica por ser a concretização da política educacional das instituições, oferecendo subsídios para o estudo.

A escolha dos Campi Sousa e Guarabira ocorreu devido às localizações geográficas em regiões distintas no Estado da Paraíba (PB). O primeiro está no 
sertão, já o segundo, no brejo paraibano, o que configura a abrangência de duas diferentes áreas do setor produtivo, ponto importante tendo em vista que o EMI integra educação e formação profissional.

Caracterizando as Instituições, iniciamos pela mais antiga, a Escola Agrotécnica Federal de Sousa. Com início das atividades em 1946, a finalidade era a de ofertar um ensino profissional para atender gratuitamente a população mais carente da região. Em 2008, por meio da Lei no 11.892/2008 que Instituiu a Rede Federal de Educação Profissional, Científica e Tecnológica, a Instituição passou a integrá-la, recebendo o atual nome de IFPB/Campus Sousa. Localizado na cidade de Sousa/PB, atualmente o Campus conta com aproximadamente 1.910 alunos matriculados nos cursos do EMI, técnico subsequente ao ensino médio, técnico subsequente ao ensino médio na modalidade da educação de jovens e adultos, educação superior e pós-graduação. Os cursos de EMI ofertados na Instituição são: Agroindústria, Agropecuária, Informática e Meio Ambiente.

Mais recente, o IFPB/Campus Guarabira foi inaugurado em 2011 e fica localizado na cidade de Guarabira/PB. Atualmente a Instituição conta com aproximadamente 810 alunos distribuídos nos cursos do EMI, técnico subsequente ao ensino médio na modalidade a distância e educação superior. Oferta os cursos de EMI em: Contabilidade, Edificações e Informática.

Uma instituição setuagenária e outra com menos de dez anos de funcionamento, mas que se coadunam em ofertar a educação profissional e tecnológica em diversos níveis e modalidades, entre os quais, o EMI.

\section{TRABALHO, EDUCAÇÃO E FORMAÇÃO HUMANA: O QUE DIZEM OS PLANOS PEDAGÓGICOS DOS CURSOS}

Temos como pressuposto que o EMI proporciona ao aluno o acesso aos conhecimentos científicos e tecnológicos, com o papel de relacionar o domínio teórico e o prático do processo produtivo. A partir disso, a reflexão caminha no sentido de analisar nos PPC's como a educação, o trabalho e a formação humana são abordados e os aspectos da integração do ensino médio à formação profissional. Para tanto, utilizamos como categorias analíticas pertinentes ao EMI: integração dos fundamentos científicos e tecnológicos; e trabalho, educação e emancipação humana.

Iniciando pelos dados que indicassem a integração dos fundamentos científicos e tecnológicos, partimos para a análise das matrizes curriculares dos PPC's. Na direção do currículo integrado, constatamos que os documentos analisados do Campus Guarabira (IFPB, 2012a; 2013; 2012b) e do Campus Sousa (IFPB, 2014a; 2014b; 2016a; 2016b) trazem uma organização por disciplinas agrupadas em três áreas: a formação geral abrange disciplinas de linguagens, ciências humanas, matemática e ciências da natureza; a formação básica para $o$ trabalho apresenta disciplinas relacionadas à língua estrangeira, informática e relações humanas e no trabalho; e a formação profissional com disciplinas técnicas específicas do curso.

A distribuição das disciplinas é feita de modo que em todos os anos da formação têm disciplinas das três áreas, oportunizando a integração entre os 
conhecimentos científicos e tecnológicos. Coaduna-se, assim, com o ideário de currículo integrado, como uma tentativa de transformar o modelo estanque no qual as disciplinas e os conteúdos são trabalhados de forma fragmentada. Essa perspectiva pode promover a visão do todo, atendendo ao:

[...] interesse em obter uma integração de campos de conhecimento e experiência que facilitem uma compreensão mais reflexiva e crítica da realidade, ressaltando não só dimensões centradas em conteúdos culturais, mas também o domínio dos processos necessários para conseguir alcançar conhecimentos concretos e, ao mesmo tempo, a compreensão de como se elabora, produz e transforma 0 conhecimento, bem como as dimensões éticas inerentes a essa tarefa. (SANTOMÉ, 1998, p. 27).

O currículo integrado é preconizado nos PPC's (IFPB, 2012a; 2012b; 2013; 2014a; 2014b; 2016a; 2016b) como necessário para que o aluno tenha acesso ao conhecimento das inter-relações existentes entre trabalho, cultura, ciência e tecnologia. Para tanto, os documentos deixam claro a atenção para que o processo formativo esteja alinhado a essa concepção, sendo desenvolvido:

[...] por meio de estratégias pedagógicas apropriadas e recursos tecnológicos fundamentados por uma sólida base cultural, científica e tecnológica, de maneira integrada na organização curricular (IFPB, 2016b, p. 17).

A integração de conhecimentos entre ensino médio e formação profissional significa considerar a realidade como a que precisa ser investigada e conhecida em suas múltiplas dimensões, apreendendo os conceitos como uma totalidade histórica e dialética. A relação entre os saberes e o contexto deve ser intrínseca, estimulando a utilização de metodologias integradoras que proporcionem a exploração das potencialidades de cada ciência de forma interdisciplinar (MOURA, 2007).

Os PPC's indicam, ainda, a apropriação do conhecimento tecnológico como o que oportuniza a vivência ostensiva no mundo do trabalho, sendo alternativa para satisfação de necessidades que a humanidade coloca e mediação entre o conhecimento científico (apreensão e desvelamento do real) e a produção (intervenção no real) (IFPB, 2012a; 2012b; 2013; 2014a; 2014b; 2016a; 2016b). Com isso, é ratificada a necessidade de integração dos conhecimentos, numa perspectiva dialética entre os fundamentos científicos e tecnológicos. Vai ao encontro da reflexão de currículo integrado a partir de Ramos (2017), quando considera que o processo de ensino visa à construção conjunta de conhecimentos gerais e específicos, no sentido de que os primeiros fundamentam os segundos e esses evidenciam o caráter produtivo concreto dos primeiros.

De acordo com Machado (2010), os conhecimentos tecnológicos são referência no EMI. Cabe promover no processo de ensino e de aprendizagem a apreensão dos conteúdos, dos métodos e das relações necessárias à compreensão, à pesquisa e à aplicação crítica e criativa das bases científicas dos processos e 
procedimentos técnicos, contextualizando-os e significando-os à luz das necessidades humanas e sociais (MACHADO, 2010).

Para que seja colocado em prática, o currículo integrado necessita que o planejamento e o desenvolvimento sejam realizados de forma coletiva, consolidando uma perspectiva educacional que assegure o diálogo permanente entre saber geral e profissional (IFPB, 2012a; 2012b). É um comprometimento com a formação humanística e tecnológica, que busca compreender como "[...] o processo produtivo (prática) está intrinsecamente vinculada aos fundamentos científico-tecnológicos (teoria), propiciando ao educando uma formação plena" (IFPB, 2014a, p. 36). A partir desse ideário, os documentos apontam uma perspectiva de formação na qual 0 aluno poderá ser capaz de:

[...] analisar criticamente os fundamentos da formação social e de se reconhecer como agente de transformação do processo histórico, considerando o mundo do trabalho, a contextualização sócio-políticoeconômica e o desenvolvimento sustentável. (IFPB, 2016b, p. 19).

A integração curricular na qual o diálogo entre as disciplinas é facilitado pode proporcionar a ampliação do campo de conhecimento do aluno, construindo melhores condições para a vida social e para o mundo do trabalho. Essa concepção está alinhada nos PPC's (IFPB, 2012a; 2012b; 2013; 2014a; 2014b; 2016a; 2016b) analisados, numa discussão que se encaminha para a superação da dualidade educacional.

No EMI, trabalho, educação e emancipação humana permeiam a formação, com o horizonte da formação humana integral, garantindo os fundamentos para que o aluno compreenda e atue de forma plena na sociedade. Coaduna, assim, com a perspectiva da educação politécnica, de modo a fundamentar a necessidade de apropriação dos conhecimentos científicos e tecnológicos, e da escola unitária na busca por romper com a dicotomia entre a educação básica e a técnica.

Nesse contexto, o trabalho é abordado nos PPC's na perspectiva de transformação da natureza e realização inerente ao ser humano, mediando o processo de produção de sua existência (IFPB, 2012a; 2012b; 2013; 2014a; 2014b; 2016a; 2016b). Assim, o trabalho é considerado como princípio educativo, que seria a forma de "[...] organização e desenvolvimento curricular em seus objetivos, conteúdos e métodos" (IFPB, 2016a, p. 18). É um processo no qual o aluno passa a ser produtor de sua própria realidade e dela pode se apropriar e transformar, orientando uma educação que reconhece a capacidade de todo ser humano desenvolver-se de maneira produtiva no seu processo de formação (RAMOS, 2017).

A formação profissional adquire um significado do trabalho como necessário para a constituição do homem como sujeito histórico-social que cria e modifica a própria existência, capaz de produzir saberes e agir social e politicamente (IFPB, 2012a; 2012b; 2013; 2014a; 2014b; 2016a; 2016b). Essa concepção permeia os documentos e a organização curricular dos cursos, inscrevendo ao EMI um caráter mais humano, com base na integração de todas as dimensões da vida ao processo educativo, rompendo com a ideia da mera transmissão de técnicas. 
O EMI descortina a possibilidade de emancipação humana, a partir de uma formação plena e que oportunize aos alunos as condições para fazer escolhas tanto para o ingresso no mundo do trabalho quanto para o prosseguimento dos estudos (IFPB, 2012a; 2012b; 2013; 2014a; 2014b; 2016a; 2016b). Representa, assim, uma estratégia fundamentada na luta pela superação do dualismo estrutural da sociedade e da educação brasileira, com o entendimento de que a política assistencialista ou de ajustamento às demandas do mercado de trabalho tendem a ser ultrapassados.

Com essa análise, constatamos nos documentos evidências da intencionalidade formativa fundamentada na politecnia e na escola unitária, que tem como perspectiva a formação humana em sua totalidade. Foi possível perceber, também, uma uniformidade na apresentação textual e organização do ideário de formação para os cursos, indicando uma padronização institucional dos documentos.

\section{CONSIDERAÇÕES FINAIS}

A concepção do EMI é ser desenvolvido de forma a garantir a conclusão do ensino médio e de uma formação profissional, contemplando o aprofundamento dos conhecimentos científicos e tecnológicos produzidos e acumulados historicamente pela sociedade. Nesse ideário de formação não há espaço para a profissionalização restrita a uma técnica ou a demandas pontuais do mercado de trabalho, mas tem como horizonte a educação politécnica e a escola unitária como referência para a emancipação humana.

A educação adquire, então, o sentido de ser um caminho essencial para uma sociedade justa e igualitária, sem distinção de classe social. Contudo, para que o processo formativo aconteça de modo significativo, é fundamental promover espaços de formação docente que propiciem aos professores reestruturarem a sua prática pedagógica, refletindo sobre o seu papel no processo de ensino.

Cabe às instituições e aos professores reconhecerem os fundamentos da formação humana integral do aluno que regem o EMI para que o currículo e a prática estejam nessa direção. Esse entendimento, sobretudo nas suas dimensões pedagógica e política, são importantes para não reproduzir uma formação propedêutica, puramente técnica ou que não tenha integração entre as áreas (SILVA, 2020).

Afinal, a integração em si não se dá apenas na forma de organização do currículo, mas na prática docente que ocorre a partir dela. Isso implica em metodologias alinhadas à concepção do EMI, além de pertencimento dos docentes a uma modalidade que tem a educação como espaço de formação para o trabalho e construção da emancipação humana. Quando a prática não acontece considerando essa perspectiva, a educação, pautada na consciência ingênua, continuará a reproduzir a dicotomia entre conhecimento teórico e prático, limitando-se aos paradigmas históricos duais. 


\section{REFERÊNCIAS}

AZEVEDO, J. M. L. A educação como política pública. Polêmicas do nosso tempo. São Paulo: Autores Associados, 2004.

BARDIN, L. Análise de conteúdo. São Paulo: Edições 70, 2016.

BRASIL. Ministério da Educação. Educação Profissional Técnica de Nível Médio Integrada ao Ensino Médio: Documento Base. Brasília, 2007. Disponível em: http://portal.mec.gov.br/setec/arquivos/pdf/documento_base.pdf. Acesso em: 16 jul. 2020.

BRASIL. Presidência da República. Decreto no 5.154, de 23 de julho de 2004. Regulamenta o $\S 2^{\circ}$ do art. 36 e os arts. 39 a 41 da Lei no 9.394, de 20 de dezembro de 1996, que estabelece as diretrizes e bases da educação nacional, e dá outras providências. Brasília, 2004. Disponível em:

http://www.planalto.gov.br/ccivil_03/_ato2004-2006/2004/decreto/d5154.htm. Acesso em: 31 maio 2020.

BRASIL. Presidência da República. Lei no 9.394, de 20 de dezembro de 1996. Estabelece as Diretrizes e Bases da Educação Nacional. Brasília, 1996. Disponível em: www.planalto.gov.br/ccivil_03/leis/L9394.htm. Acesso em: 20 jan. 2020.

BRASIL. Presidência da República. Lei no 11.892, de 29 de dezembro de 2008. Institui a Rede Federal de Educação Profissional, Científica e Tecnológica, cria os Institutos Federais de Educação, Ciência e Tecnologia, e dá outras providências. Brasília, 2008. Disponível em: http://www.planalto.gov.br/ccivil_03/_ato20072010/2008/lei//11892.htm. Acesso em: 12 jul. 2018.

CIAVATTA, M. A formação integrada: a escola e o trabalho como lugares de memória e identidade. Trabalho Necessário, Niterói, v. 3, n. 3. p. 01-20, 2005. Disponível em: http://periodicos.uff.br/trabalhonecessario/issue/view/266. Acesso em: 20 jan. 2020.

GRAMSCI, A. Os intelectuais e a organização da cultura. Rio de Janeiro: Civilização Brasileira, 1988.

GRAMSCI, A. Cadernos do cárcere. Os intelectuais. O princípio educativo. Jornalismo, v. 2, 2. ed. Rio de Janeiro: Civilização Brasileira, 2001.

INSTITUTO FEDERAL DE EDUCAÇÃO, CIÊNCIA E TECNOLOGIA DA PARAÍBA. Campus Guarabira. Plano Pedagógico de Curso Técnico Integrado ao Médio em Contabilidade. Guarabira, 2012a. Disponível em:

https://estudante.ifpb.edu.br/media/cursos/77/documentos/CONTABILIDADE_Integra do_2012_GUARABIRA.pdf. Acesso em: 20 jan. 2020.

INSTITUTO FEDERAL DE EDUCAÇÃO, CIÊNCIA E TECNOLOGIA DA PARAÍBA. Campus Guarabira. Plano Pedagógico de Curso Técnico Integrado ao Médio em Informática. Guarabira, 2012b. Disponível em: https://estudante.ifpb.edu.br/media/cursos/75/documentos/ppc-informatica.pdf. Acesso em: 20 jan. 2020.

INSTITUTO FEDERAL DE EDUCAÇÃO, CIÊNCIA E TECNOLOGIA DA PARAÍBA. Campus Guarabira. Plano Pedagógico de Curso Técnico Integrado ao Médio em Edificações. Guarabira, 2013. Disponível em: 
https://estudante.ifpb.edu.br/media/cursos/76/documentos/integrado_edificacoes_gu arabira_uhSyrrs.pdf. Acesso em: 20 jan. 2020.

INSTITUTO FEDERAL DE EDUCAÇÃO, CIÊNCIA E TECNOLOGIA DA PARAÍBA. Campus Sousa. Plano Pedagógico de Curso Técnico Integrado ao Médio em Agroindústria. Sousa, 2014a. Disponível em: https://estudante.ifpb.edu.br/media/cursos/128/documentos/PPC_AGROIND_OK__Copia.pdf. Acesso em: 20 jan. 2020.

INSTITUTO FEDERAL DE EDUCAÇÃO, CIÊNCIA E TECNOLOGIA DA PARAÍBA. Campus Sousa. Plano Pedagógico de Curso Técnico Integrado ao Médio em Agropecuária. Sousa, 2014b. Disponível em: https://estudante.ifpb.edu.br/cursos/127. Acesso em: 20 jan. 2020.

INSTITUTO FEDERAL DE EDUCAÇÃO, CIÊNCIA E TECNOLOGIA DA PARAÍBA. Campus Sousa. Plano Pedagógico de Curso Técnico Integrado ao Médio em Informática. Sousa, 2016a. Disponível em: https://estudante.ifpb.edu.br/media/cursos/126/documentos/PPC__Inform\%C3\%A1tica_-_Integrado_-_2016.pdf. Acesso em: 20 jan. 2020.

INSTITUTO FEDERAL DE EDUCAÇÃO, CIÊNCIA E TECNOLOGIA DA PARAÍBA. Campus Sousa. Plano Pedagógico de Curso Técnico Integrado ao Médio em Meio Ambiente. Sousa, 2016b. Disponível em: https://estudante.ifpb.edu.br/media/cursos/129/documentos/PPC_INTEGRADO_NO VO_revisado.pdf. Acesso em: 20 jan. 2020.

MACHADO, L. R. de S. Ensino médio e técnico com currículos integrados: propostas de ação didática para uma relação não fantasiosa. In: MOLL, J. (Org.). Educação profissional e tecnológica no Brasil contemporâneo: desafios, tensões e possibilidades. Porto Alegre: Artmed, 2010. p. 80-94.

MARX, K. O Capital: crítica da economia política. Livro 1, v. 1. São Paulo: Nova Cultural Ltda, 1996.

MARX, K.; ENGELS, F. Textos sobre educação e ensino. Campinas: Navegando, 2011.

MOURA, D. H. Educação básica e educação profissional e tecnológica: dualidade histórica e perspectivas de integração. Holos, Natal, v. 2, ano 23, p. 04-30, 2007. Disponível em: http://www2.ifrn.edu.br/ojs/index.php/HOLOS/article/view/11. Acesso em: 20 jan. 2020.

RAMOS, M. Ensino médio integrado: lutas históricas e resistências em tempos de regressão. In: ARAÚJO, A. C.; SILVA, C. N. N. da (orgs.). Ensino médio integrado no Brasil: fundamentos práticas e desafios. Brasília: Ed. IFB, 2017. p. 20-43.

SANTOMÉ, J. T. Globalização e interdisciplinaridade: o currículo integrado. Porto Alegre: Artes Médicas, 1998.

SILVA, C. M. B. da. Ensino médio integrado: escola unitária como horizonte?

Revista Brasileira da Educação Profissional e Tecnológica, Natal, v. 2, n. 19, p. 01-15, 2020. Disponível em: http://www2.ifrn.edu.br/ojs/index.php/RBEPT/article/view/9729. Acesso em: 14 jun. 2020. 